\title{
MORFOMETRIA DO OSSO ESTERNO E SUA CORRELAÇÃO COM O VOLUME PULMONAR
}

\author{
Grasielle Silva Santos ${ }^{1}$ \\ Déborah Borges de Sousa Mendes ${ }^{2}$ \\ Gabriela Parreira Bizinoto ${ }^{3}$ \\ Amanda Braga Munuera ${ }^{4}$ \\ Rogério Silva Santos ${ }^{5}$ \\ Kleber Fernando Pereira ${ }^{6}$ \\ Ana Claudia de Laet Segantine ${ }^{7}$ \\ Cláudio Silva Teixeira ${ }^{8}$
}

SANTOS, G. S.; MENDES, D. B. de S.; BIZINOTO, G. P.; MANUERA, A. B.; SANTOS, R. S.; PEREIRA, K. F.; SEGANTINE, A. C. de L.; TEIXEIRA, C. S. Morfometria do osso esterno e sua correlação com o volume pulmonar. Arq. Cienc. Saúde UNIPAR, Umuarama, v. 22, n. 2, p, 95-98, maio/ago. 2018.

\begin{abstract}
RESUMO: Este estudo teve por objetivo desenvolver um modelo matemático que a partir da extensão do osso esterno fornecesse o tamanho do pulmão compatível para o receptor. Foram coletadas as medidas antropométricas do tórax de 250 indivíduos, através de exame de tomografia computadorizada. Os resultados apontam que a medida do osso esterno (distância da incisura jugular até processo xifóide) apresenta correlação positiva com todas as outras medidas do tórax (medida ântero-posterior e látero-medial entre II e III costela, e ápice à base de ambos os pulmões). Entretanto, o volume pulmonar e sua relação com o osso esterno apresentam discrepâncias quando analisados sob a correlação de Pearson, pois a relação entre a medida da incisura jugular ao processo xifóide e a medida do ápice à base do pulmão direito e esquerdo, apresenta correlação positiva média $(0,31-0,6)$. Já a medida da incisura jugular ao processo xifóide com a medida ântero-posterior e látero-medial do tórax, apresenta correlação significativa baixa (0-0,3). Então, a análise estatística da correlação de Pearson demonstrou ser inviável o desenvolvimento da fórmula, pois esta não seria confiável já que funcionaria para cerca de apenas $39 \%$ dos pacientes. Assim, o melhor método para determinar o doador para o transplante, continua sendo a análise de fatores de risco, a capacidade vital forçada do doador e receptor com estatura maior do que a do doador.
\end{abstract}

PALAVRAS-CHAVE: Compatibilidade. Medidas do tórax. Osso esterno. Transplante pulmonar.

\section{STERNUM BONE MORPHOLOGY AND ITS CORRELATION WITH LUNG VOLUME}

ABSTRACT: This study aimed at developing a mathematical model that can provide the compatible lung size for the recipient from the length of the sternum bone. Anthropometric chest measurements of 250 individuals were collected through a CT scan. The results indicate that the measurement of the sternum bone (distance from the jugular notch to the xiphoid process) shows a positive correlation with all other thorax measurements (antero-posterior and medial-posterior measurement between ribs II and III, and apex-to-base on both lungs). However, lung volume and its correlation to the sternal bone present discrepancies when analyzed under Pearson's correlation, since the relation between the jugular notch measurement and the apex measurement at the base of the right and left lungs shows a positive correlation mean (0.31-0.6). The measurement of the jugular notch in the xiphoid process with the anterior-posterior and medial-medial measurements, presents a low significant correlation (0-0.3). Therefore, the statistical analysis of the Pearson's correlation showed that the formula could not be applied since it would not be reliable since it would work for only $39 \%$ of the patients. Thus, the best method to determine the donor for transplantation remains the analysis of risk factors, the forced vital capacity of the donor, and the recipient being taller than the donor.

KEYWORDS: Chest measurements. Compatibility. Lung Transplant. Sternal Bone.

\section{Introdução}

O transplante pulmonar é uma terapia para pacientes com doenças pulmonares terminais não neoplásicos. Atualmente, existem diferentes modalidades para o transplante pulmonar, como: transplante unilateral, transplante bilateral sequencial, transplante cardiopulmonar e transplante lobar (CAMARGO, 2014). Dentre estas modalidades de transplan- te, o bilateral demonstrou sobrevida maior principalmente em pacientes com fibrose pulmonar idiopática, contudo, em pacientes com doença pulmonar obstrutiva crônica não houve diferença (SCHAFFER et al., 2015; WEILL et al., 2015).

Teve início na década de 80 e, tem-se realizado cerca de 2500 transplantes por ano em todo o mundo. Um dos desafios enfrentados na técnica de transplante pulmonar é estabelecer a compatibilidade de tamanho entre o pulmão do

DOI: 10.25110 /arqsaude.v22i2.2018.6175

${ }^{1}$ Ex-bolsista Pibic, médica graduada pela Faculdade de Medicina da Universidade de Rio Verde- Campus Rio Verde. Rua das Paineiras, quadra 2, lote 6, Jardins Lisboa- Goiânia-Goiás. CEP: 74357-030. Telefone: (62)99910-8818. Email: grasivips@hotmail.com

${ }^{2}$ Médica graduada pela faculdade de Medicina da Universidade de Rio Verde- Campus Rio Verde. Rua Comendador Negrão de Lima, ${ }^{\circ}$ 151, apartamento 1502 A, Negrão de Lima -Goiânia- Goiás. CEP: 74650-030. Telefone: (64) 98147-4847. E-mail: deborah bsm@hotmail.com

${ }^{3}$ Médica graduada pela Faculdade de Medicina da Universidade de Rio Verde-Campus Rio Verde. Rua S3, nº 50, apartamento 1902, edifício Sofisticatto, Bela Vista- Goiânia- Goiás. CEP: 74823-440. Telefone: (62)98152-6648. E-mail: amgabrielapb@gmail.com

${ }^{4}$ Discente do Curso de Medicina da Faculdade de Medicina da Universidade de Rio Verde- Campus Rio Verde. Rua Costa Gomes, n ${ }^{\circ} 987$, Centro- Rio VerdeGoiás. CEP: 75901-050. Telefone: (64) 98138-9385. E-mail: amandabragamunuera@gmail.com

${ }^{5}$ Residente em Cirurgia Plástica no Hospital Geral de Goiânia Alberto Rassi (HGG). Rua das Paineiras, quadra 2, lote 6, Jardins Lisboa- Goiânia-Goiás. CEP 74357-030. Telefone (62) 98236-6140. E-mail: drpragma@hotmail.com

${ }^{6}$ Professor Adjunto III da Universidade Federal de Goiás - Regional Jataí, Universidade Federal de Goiás - Regional Jataí, BR 364, Km 195, n. 3800. Jataí. Goiás, Brasil. CEP 75.801-615. Tefone: (64) 3606-8347. Email: kpereiraufg@gmail.com

${ }^{7}$ Discente de pós-graduação stricto sensu (Mestrado) em Biociência Animal UFG - Regional Jataí. E-mail: acdlsegantine@gmail.com

${ }^{8}$ Orientador. Universidade de Rio Verde. E-mail: claudioanatomia@yahoo.com.br 
doador e a caixa torácica do receptor (JATENE; PÊGO-FERNANDES; MEDEIROS, 2009; CAMARGO et al., 2015; JUNIOR et al., 2015). Tem-se como as indicações gerais para a seleção do receptor: expectativa média de vida menor do que 2 a 3 anos, tratamento inefetivo, estado nutricional aceitável, idade menor que 65 anos, doença pulmonar obstrutiva, restritiva, supurativa e vascular (DIRETRIZES, 2012).

Quanto ao método mais confiável para determinar a compatibilidade no transplante pulmonar é o de comparar o volume pulmonar do doador e do receptor, baseando em idade, sexo e altura. Se o pulmão exceder a capacidade da caixa torácica pode haver dificuldades hemodinâmicas no fechamento do tórax ao final do procedimento (FERNANDEZ , PATTERSON, 2009).

Este estudo teve como objetivo desenvolver um modelo matemático que a partir do comprimento do osso esterno fornecesse o tamanho do pulmão compatível para o receptor.

\section{Materiais e Métodos}

O presente trabalho é um estudo de campo descritivo macroscópico somente por tomografia, com abordagem quantitativa que visou analisar o tamanho do osso esterno, relacionado à medida dos pulmões e ao diâmetro do tórax de indivíduos saudáveis. Não foram feitas mensurações diretamente no paciente uma vez que seria impossível realizar a medida dos pulmões em pacientes vivos e correlacioná-la com as demais.

A base de dados principal foi organizada por um professor médico radiologista em conjunto com acadêmicos do curso de medicina em um hospital na cidade de Rio Verde - Goiás, em um total de 250 indivíduos, onde cada paciente, com o pedido de tomografia, autorizou a pesquisa assinando um Termo de Consentimento Livre e Esclarecido. A cada exame ocorrido foi preenchido um formulário com informações sobre medidas antropométricas do tórax. As medidas analisadas foram adquiridas por meio do programa Osirix. Ao qual permitiu obter as medidas estudadas em até três dimensões, com insignificante margem de erro. Este projeto foi aprovado pelo comitê de ética da Universidade de Rio Verde com o parecer número 842.638/2014.

$\mathrm{O}$ formulário consistia em onze medidas estabelecidas pelos pesquisadores, para determinar se existia relação e posteriormente definir um protocolo, caso o resultado fosse o esperado dentro da pesquisa. As medidas em relação ao tórax consistiram em: medida do osso esterno (distância da incisura jugular ao final do processo xifóide), ápice do pulmão (direito e esquerdo) até a base, medida látero-medial entre a II e III costela (pulmão direito e esquerdo), medida látero-medial entre a VI e VII costela (pulmão direito e esquerdo), medida ântero-posterior entre a II e III costela de ambos os pulmões e de forma análoga entre a VI e a VII costela.

Após a coleta de todos os dados, os resultados foram submetidos à análise estatística por meio do pacote estatístico SPSS, versão 12, no qual abordou os níveis de significância das medidas apresentadas e a correlação de Pearson.

\section{Resultados e Discussão}

O volume pulmonar apresentou discrepâncias quando analisados sob a correlação de Pearson. Observa-se na Tabela 1, que a medida do ápice do pulmão direito até a base (APD) e o ápice do pulmão esquerdo até a base (APE) apresentam uma correlação positiva alta (0,61-1). Entretanto, quando relacionam estas medidas com a medida da incisura jugular ao processo xifóide (DIP), tem-se uma correlação positiva média $(0,31-0,6)$. Nas medidas ântero-posterior (MAP) e látero-medial dos pulmões direito e esquerdo (MLM), a correlação foi ainda menor $(0-0,3)$. Tais diferenças entre as correlações impossibilitaria estabelecer relações matemáticas entre as medidas necessárias para a compatibilidade no transplante pulmonar. Menna-Barreto (2002), descreveu a classificação dos volumes pulmonares em estáticos (absolutos) e dinâmicos. Os volumes pulmonares estáticos são os resultantes da complementação de manobras respiratórias, consistindo em compartimentos pulmonares. Os volumes pulmonares dinâmicos são os decorrentes de manobras respiratórias forçadas, expressam variáveis e parâmetros de fluxo aéreo e são medidos através da espirometria. Entretanto, o autor não relata sobre a relação entre a morfometria do osso esterno e o volume pulmonar, independente de qual volume desejaria estabelecer, estático ou dinâmico.

Tabela 1: Correlação de Pearson

\begin{tabular}{c|c|c|c|c}
\hline N (250) & APD2 & APE3 & MAP4 & MLM5 \\
\hline APD2 & 1 & $0,867^{* *}$ & & \\
\hline DIP1 & $0,394 * *$ & $0,367 * *$ & $0,135^{*}$ & $0,299^{* *}$ \\
\hline
\end{tabular}

${ }^{\mathrm{T}}$ Distância da incisura jugular ao processo xifoide, ${ }^{2}$ Medida do ápice do pulmão direito até a base, ${ }^{3}$ Medida do ápice do pulmão esquerdo até a base, ${ }^{4}$ Medida ântero-posterior, ${ }^{5}$ Medida látero-medial

*Correlação significativa no nível de 0,05

** Correlação significativa no nível de 0,01

Na Tabela 2, quando se compara a medida da incisura jugular ao processo xifóide com todas as outras medidas do tórax, observa-se diferença significativa entre as medidas ântero-posterior do pulmão direito (entre II e III costela, e entre VI e VII costela), medida látero-medial (entre II e III costela, e entre VI e VII costela) de ambos os pulmões e as medidas do ápice à base dos pulmões direito e esquerdo. Porém, quando se compara a medida da incisura jugular ao processo xifóide com a medida ântero-posterior do pulmão esquerdo (entre II e III costela) e a medida ântero-posterior do pulmão esquerdo (entre VI e VII costela), não existem diferenças significativas. Diante disso, é inviável estabelecer a relação entre esterno e volume pulmonar. 
Tabela 2: Nível de significância entre a distância da incisura jugular ao processo xifóide e as demais medidas

\begin{tabular}{|c|c|}
\hline Regiões Analisadas & $\mathbf{P}$ \\
\hline $\begin{array}{l}\text { Distância da incisura jugular ao processo } \\
\text { xifoide }(\mathrm{cm})\end{array}$ & 1 \\
\hline $\begin{array}{l}\text { Medida ântero-posterior pulmão direito (entre } \\
\text { II e III costela) }(\mathrm{cm})\end{array}$ & $* 0,032$ \\
\hline $\begin{array}{l}\text { Medida ântero-posterior pulmão esquerdo } \\
\text { (entre II e III costela) }(\mathrm{cm})\end{array}$ & $* * 0,090$ \\
\hline $\begin{array}{l}\text { Medida ântero-posterior pulmão direito (entre } \\
\text { VI e VII costela) }(\mathrm{cm})\end{array}$ & $* 0,000$ \\
\hline $\begin{array}{l}\text { Medida ântero-posterior pulmão esquerdo } \\
\text { (entre VI e VII) }(\mathrm{cm})\end{array}$ & $* * 0,240$ \\
\hline $\begin{array}{l}\text { Medida látero-medial do pulmão direito (entre } \\
\text { II e III costela) }(\mathrm{cm})\end{array}$ & $* 0,001$ \\
\hline $\begin{array}{l}\text { Medida látero-medial do pulmão esquerdo } \\
\text { (entre II e III costela) }(\mathrm{cm})\end{array}$ & $* 0,001$ \\
\hline $\begin{array}{l}\text { Medida látero-medial do pulmão direito (entre } \\
\text { VI e VII costela) }(\mathrm{cm})\end{array}$ & $* 0,000$ \\
\hline $\begin{array}{l}\text { Medida látero-medial do pulmão esquerdo } \\
\text { (entre VI e VII costela) }(\mathrm{cm})\end{array}$ & $* 0,000$ \\
\hline Medida ápice à base do pulmão esquerdo $(\mathrm{cm})$ & $* 0,000$ \\
\hline Medida ápice à base do pulmão direito (cm) & $* 0,000$ \\
\hline
\end{tabular}

Não há um método disponível que garanta um tamanho pulmonar apropriado em relação à caixa torácica, e ainda não se estabeleceu qual a melhor abordagem para a verificação dessa compatibilidade de tamanho. Acredita-se que a incompatibilidade de tamanho entre doador e receptor conduz a problemas clínicos e funcionais pós-transplante, entre eles pneumotórax persistente, atelectasia persistente, maior tempo de internação na unidade de tratamento intensivo e diminuição da capacidade máxima de exercício em longo prazo (OUWENS et al., 2002).

Estudos realizados por Ouwens e colaboradores (2002), avaliaram a capacidade pulmonar de 98 pacientes que fizeram transplantes pulmonares. Neste, mensurou-se a capacidade pulmonar total (CPT) calculada a partir da altura e sexo do doador e do receptor, como medida de avaliação da compatibilidade de tamanho pulmonar. Consequente à incompatibilidade do tamanho pulmonar, foi necessário à redução perioperatória do pulmão do doador em 24 transplantes.

Desta forma, Chen e colaboradores (2013) declaram critérios para possíveis doadores no transplante pulmonar, onde são parâmetros estabelecidos: parentes de até terceiro grau, idade entre 20 e 60 anos, volume expiratório forçado no primeiro segundo $\geq 85 \%$ e ausência de patologia pulmonar significativa na tomografia computadorizada, demonstrando correlação positiva entre o doador e os volumes pulmonares antes e após o transplante, sendo que enxertos de doadores de tamanho inferior obtiveram maior expansão.

Com base nos dados morfométricos encontrados na presente pesquisa, não foi possível a criação de um modelo matemático que possibilizasse predizer de maneira satisfatória a CPT e o tamanho do pulmão tanto do doador quanto do receptor, uma vez que essa correlação só daria certo para a minoria dos pacientes (Correlação de Pearson Média- 0,31-0,6).
Dessa forma, estes achados não corroboram com o descrito por Fernandez e Patterson (2009), baseado em nomogramas que utilizam sexo, idade e altura, para estimar a compatibilidade do volume pulmonar do doador e do receptor.

Além disso, os resultados corroboram com o que foi elucidado por Jatene; Pêgo-Fernandes e Medeiros (2009), definiram que somente 15 a $20 \%$ dos pulmões viabilizados são efetivamente empregados, sendo a seleção para o transplante de pulmão ainda um desafio para a prática médica, tendo em vista a mortalidade pós-operatória. Assim, o melhor método continua sendo a análise de fatores de risco, a capacidade vital forçada do doador e receptor com estatura maior do que o doador.

\section{Conclusão}

Este estudo mostra uma correlação positiva entre a medida do esterno em função do volume pulmonar e seus valores são insuficientes para o desenvolvimento de uma fórmula e de um novo método que seja capaz de definir a compatibilidade entre doador e receptor. Dessa forma, a incompatibilidade entre doadores e receptores será sempre um estímulo para que pesquisadores possam descobrir novas formas de amenizar o resultado desfavorável.

\section{Agradecimentos}

À UniRV pela concessão de bolsas, ao orientador Prof. Me. Cláudio Silva Teixeira, pela oportunidade da realização da pesquisa, revisão e sugestões, aos colegas pela contribuição, e ao Hospital Santa Terezinha pela disponibilização para coleta de dados.

\section{Referências}

ALBERT EINSTEIN HOSPITAL ISRAELITA. Diretrizes assistenciais: preparo e acompanhamento do transplante de pulmão. Disponível em: <http://docplayer.com.br/7750100Diretrizes-assistenciais-preparo-e-acompanhamento-dotransplante-de-pulmao.html>. Acesso em: 10 out. 2017.

AFONSO JUNIOR, J. E. et al. Transplante pulmonar. Einstein, v. 13, n. 2, p. 297-304, 2015.

CAMARGO, J. J. Transplante de pulmão: indicações atuais. Pulmão, Rio de |Janeiro, v. 23, n. 1, p. 36-44, 2014.

CAMARGO, P. C. L. B. et al. Transplante pulmonar: abordagem geral sobre seus principais aspectos. J Bras Pneumol. v. 41, n. 6, p. 547-553, 2015.

CHEN, F. et al. Adaptation over a wide range of donor graft lung size discrepancies in living-donor lobar lung transplantation. American Journal of Transplantation, v. 13, n. 5, p. 1336-1342, 2013.

FERNANDEZ, F. G.; PATTERSON, G. A. Lung transplantation. In: SHIELDS, T. W. et al. General thoracic surgery. Philadelphia: Lippincott Williams \& Wilkins, 2009. p. 1241-1263. 
JATENE, F. B.; PÊGO-FERNANDES, P. M.; MEDEIROS, I. L. Transplante pulmonar. Revista de Medicina, v. 88, n. 3, p. 111-122, 2009.

MENNA-BARRETO, S. S. Volumes pulmonares. J

Pneumol. v. 28, n. 3, p. 83-94, 2002.

OUWENS, J. P. et al. Size matching in lung transplantation using predicted total lung capacity. European Respiratory Journal, v. 20, n. 6, p. 1419-1422, 2002.

SCHAFFER, J. M. et al. Single-vs double-lung transplantation in patients with chronic obstructive pulmonary disease and idiopathic pulmonary fibrosis since the implementation of lung allocation based on medical need. Jama, v. 313, n. 9, p. 936-948, 2015.

WEILL, D. et al. A consensus document for the selection of lung transplant candidates: 2014--an update from the Pulmonary Transplantation Council of the International Society for Heart and Lung Transplantation. J Heart Lung Transplant. v. 34, n. 1, p. 1-15, 2015.

Recebido em: 24/05/2017 Aceito em: 02/02/2018 